\title{
Virtual Remaining Life Assessment of Electronic Hardware Subjected to Shock and Random Vibration Life Cycle Loads
}

\author{
Sony Mathew, Diganta Das, Michael Osterman, and Michael Pecht, \\ Center for Advanced Life Cycle Engineering (CALCE), University of Maryland \\ Robin Ferebee, NASA Marshall Space Flight Center \\ Joseph Clayton, BD Systems, Inc.
}

\begin{abstract}
This study presents a physics-of-failure-based virtual remaining life assessment method for assessing the remaining life of an electronic circuit card. The approach is then demonstrated through a case study of a circuit card assembly in the Space Shuttle solid rocket booster. Using thermal and mechanical stress damage models, the accumulated damage in the circuit card due to the life cycle environment loads on the card was calculated. Based on the amount of damage accumulated, the remaining life of the circuit card was estimated.
\end{abstract}

\section{KEYWORDS}

Remaining life, shock, random vibration, solder interconnects, life cycle, damage

\section{INTRODUCTION}

The reliable life of an electronics product is a function of the stresses the product experiences during its lifetime, including manufacture, assembly, testing, storage, handling, transportation, and operation. The effect of the stresses can be manifested as degradation in performance or gradual loss of durability of the elements in the product. Accumulated damage is another measure of degradation that often cannot be directly detected by performance loss. Damage can occur and accumulate during the life phases and affect the reliability of the electronic hardware. ${ }^{1}$ In order to quantify the damage accumulated in the electronic hardware and to determine how long the hardware can operate without failure under similar stresses in the future, a remaining life assessment needs to be conducted. A remaining life assessment estimates the ability of the electronic hardware to meet the required performance specifications in the life cycle application environment for the remaining service life of the product. $^{2}$

Several general-purpose software tools are used to evaluate the stresses within electronic hardware. ${ }^{3}$ Assessment of reliability using these general-purpose software tools is time consuming. The Center for Advanced Life Cycle Engineering (CALCE) at the University of Maryland, College Park, has developed software to conduct a quick assessment - one that provides a fairly approximate estimate of the required output with limited inputs. The software is a physics-of-failure-based tool for rapid evaluation of interconnect reliability. This software has been used successfully in the past to conduct virtual qualification of electronic hardware. ${ }^{2-7}$

The software consists of a set of simulation tools that use various thermal and mechanical stress and damage models. ${ }^{4}$ Appropriate damage models are used to calculate the damage caused due to each type of life cycle load condition experienced by the circuit card. Assuming the future life cycle loading conditions will follow the same pattern as the past load history, the total damage accumulated for one future life cycle is calculated. Based on the values of the damage to date and the damage per future life cycle, the remaining life is estimated.

The electronic hardware under study is part of the integrated electronic assembly (IEA) of one of the Space Shuttle's solid rocket boosters (SRBs). The IEAs control the launch, ascent, separation, reentry, and recovery of the booster. ${ }^{8}$ The electronic circuit cards in the IEA are 
subjected to random vibration, shock, and thermal loads during their life cycles. In the past, after an SRB has completed its flight (mission) and upon recovery from the sea, some circuit cards in the IEA have shown electronic component and component lead failures; the causes of these failures were identified and rectified. The causes were attributable to improper selection of components for the application conditions. The objective of this study was to determine the number of future missions in which the hardware under study could be used without failure. This study utilizes the ability of the software to calculate the damage accumulated in the solder joint interconnects of a circuit card to determine the remaining life of the circuit card.

\section{ELECTRONIC HARDWARE UNDER STUDY}

The circuit card under study is a rectangular, single-sided circuit card with FR4 substrate, on which resistors, capacitors, diodes, transistors, transformer assemblies, connector, and optocouplers are mounted. All but four transistors and two transformers are insertion-mount components. The four transistors are mounted on the aluminum brackets that are part of the aluminum wedge frame riveted to the circuit card. The two transformers are attached to the center of the circuit card with screws. The C-shaped aluminum frame on the circuit card is used to slide the circuit card into the birtcher guides in the IEA box. Figure 1 shows the circuit card and the aluminum frame riveted to it.

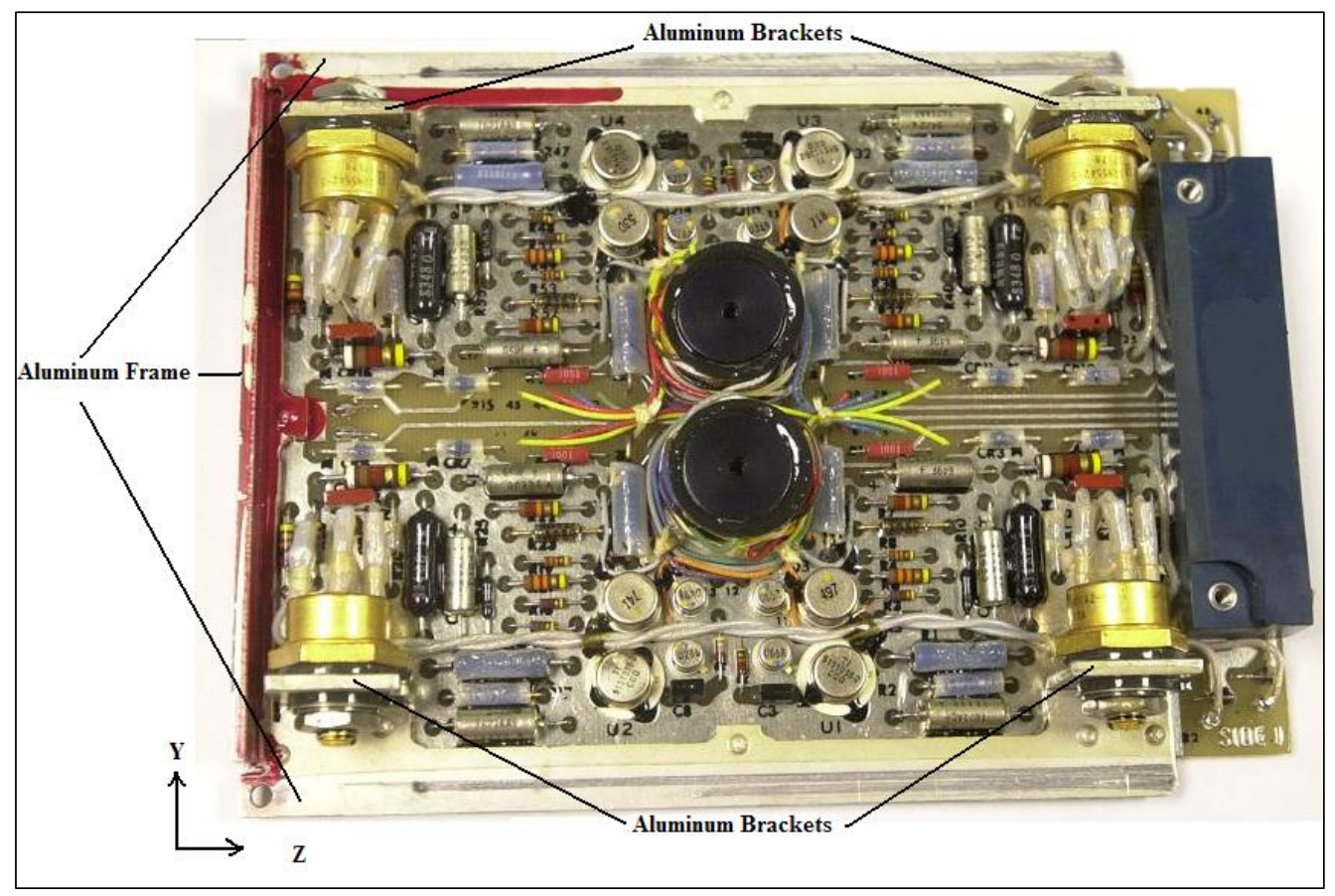

Figure 1. Circuit card under review.

\section{LIFE CYCLE ENVIRONMENT OF IEA CIRCUIT CARD}

The circuit card has been used for eight space missions. During the first flight, vibration isolation was not provided for the IEA box. For the next seven flights, vibration isolation was provided. During flight, the circuit card experiences random vibrations and experiences shock upon water impact. During the preflight acceptance tests, the IEA is subjected to random 
vibration and temperature cycling loads. The circuit card also experiences stresses during storage, transportation, and recovery phases of its life cycle. Table 1 shows the life cycle condition, the type of loads, and the number of exposures of the circuit card for each condition.

Table 1. Life cycle load history.

\begin{tabular}{|l|l|c|}
\hline Life Cycle Condition & Load Type & $\begin{array}{c}\text { Number of Exposures } \\
\text { to Date }\end{array}$ \\
\hline Vibration acceptance test & Random vibrations & 15 \\
\hline Thermal acceptance test & Temperature cycling & 27 \\
\hline Flight (vibration non-isolated) & Random vibration and shock & 1 \\
\hline Flight (vibration isolated) & Random vibration and shock & 7 \\
\hline
\end{tabular}

\section{Random vibration loads}

The circuit card experiences varying intensity of random vibration during the entire flight sequence of an SRB. Figure 2 shows the vibration time history of one flight of an SRB. The vibration time history was modeled as 32 discrete events from the pre-launch stage to the splashdown. The power spectral density (PSD) profile representing the vibration load for each event was generated. The occurrences of the events at different stages of the flight are also shown. The even-numbered sections indicate the major events, while the transition events are odd numbered and are not displayed. The $32 \mathrm{nd}$ event is the shock due to water impact. The vibration profile was recorded by an accelerometer fixed on the casing of an IEA. A contractor for the National Aeronautics and Space Administration (NASA) used finite element modeling and transfer functions to transform the field data into PSD profiles for each of the 32 events.

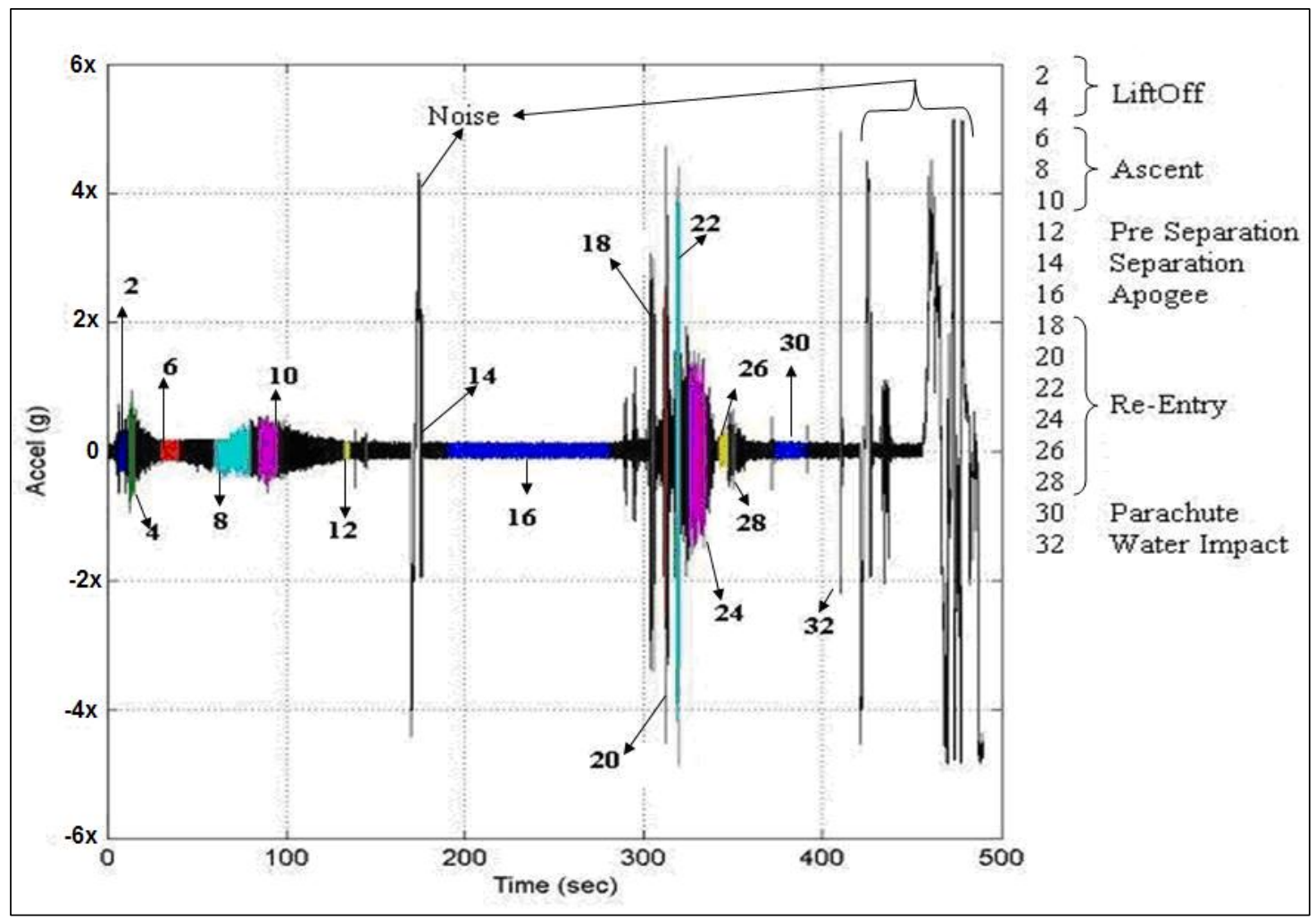

Figure 2. Vibration time history for one flight. 
The circuit cards in the IEA are subjected to random vibrations during vibration acceptance testing. A total of 15 tests with durations of $60 \mathrm{sec}$ each in all three axes of the circuit card were conducted. NASA provided the vibration PSD profile applied to the circuit card during an acceptance test. The IEA box is transported from the storage site to the launch preparation site by road. During transportation, the IEA box is placed on vibration and shock absorbers. Therefore, the loads from transportation are not used.

\section{Shock load}

On its way to splashdown, an SRB is considerably slowed by the opening of the drogue chute and later the main parachutes. Even with this slowing, an SRB experiences a shock upon water impact. The shock information provided for the circuit card was available in the form of acceleration (g) vs time. The contractor used finite element modeling software to transform field data into shock profiles for the circuit card.

\section{Temperature conditions}

The circuit card is subjected to temperature conditions during pre-launch standby, flight, acceptance tests, recovery, and storage. The pre-launch thermal environment is close to the ambient temperature. The huge mass of an SRB contributes in keeping the temperature close to ambient during the pre-launch operations. The in-flight temperature rise of the IEA is small. The recorded temperature values show less than a $1 \mathrm{C}^{\circ}\left(33.8 \mathrm{~F}^{\circ}\right)$ rise in the IEA temperature. During the 6 min of flight, the operating temperature of the circuit card is close to $33^{\circ} \mathrm{C}\left(91.4{ }^{\circ} \mathrm{F}\right)$.

Two types of thermal acceptance tests are conducted on the IEA per flight: the acceptance test (ATP) and the burn-in test (MCO). The MCO includes a 5-hr soak time at each set point after which a functional test is conducted at ambient, cold, hot, cold, hot, and ambient conditions. For the ATP, the soak time at each set point is again $5 \mathrm{hr}$ after which a functional test is conducted at ambient, cold, hot, and ambient conditions. A total of 27 temperature tests have been conducted on the card under review.

During the recovery stage, an SRB is dragged by towboats from the site of splashdown to the port facilities of the launch site. The IEA experiences some temperature variation during this period. The IEA is usually stored indoors and the general temperature ranges between 15.5 and $26.6^{\circ} \mathrm{C}\left(59.9-79.88^{\circ} \mathrm{F}\right)$.

\section{VIRTUAL REMAINING LIFE ASSESSMENT}

A virtual remaining life assessment of the circuit card was conducted to estimate the number of future missions for which the circuit card can be used without failure. The virtual remaining life assessment process consists of the following steps: 1) design capture; that is, generation of a software model of the circuit card using the geometry and material data of the card and components; 2) load history characterization; that is, selection of life cycle loads and their simplification for analysis; 3) load transformation; that is, application of characterized loads to the software model to obtain the responses of the loads on the card; 4) damage assessment; that is, estimation of the damage to the interconnections of each component; and 5) calculation of the remaining life of the circuit card. The software was used to calculate the damage accumulated in the interconnects of the components on the circuit card. The process flow for the simulation of time-to-failure calculation is shown in Figure 3. 


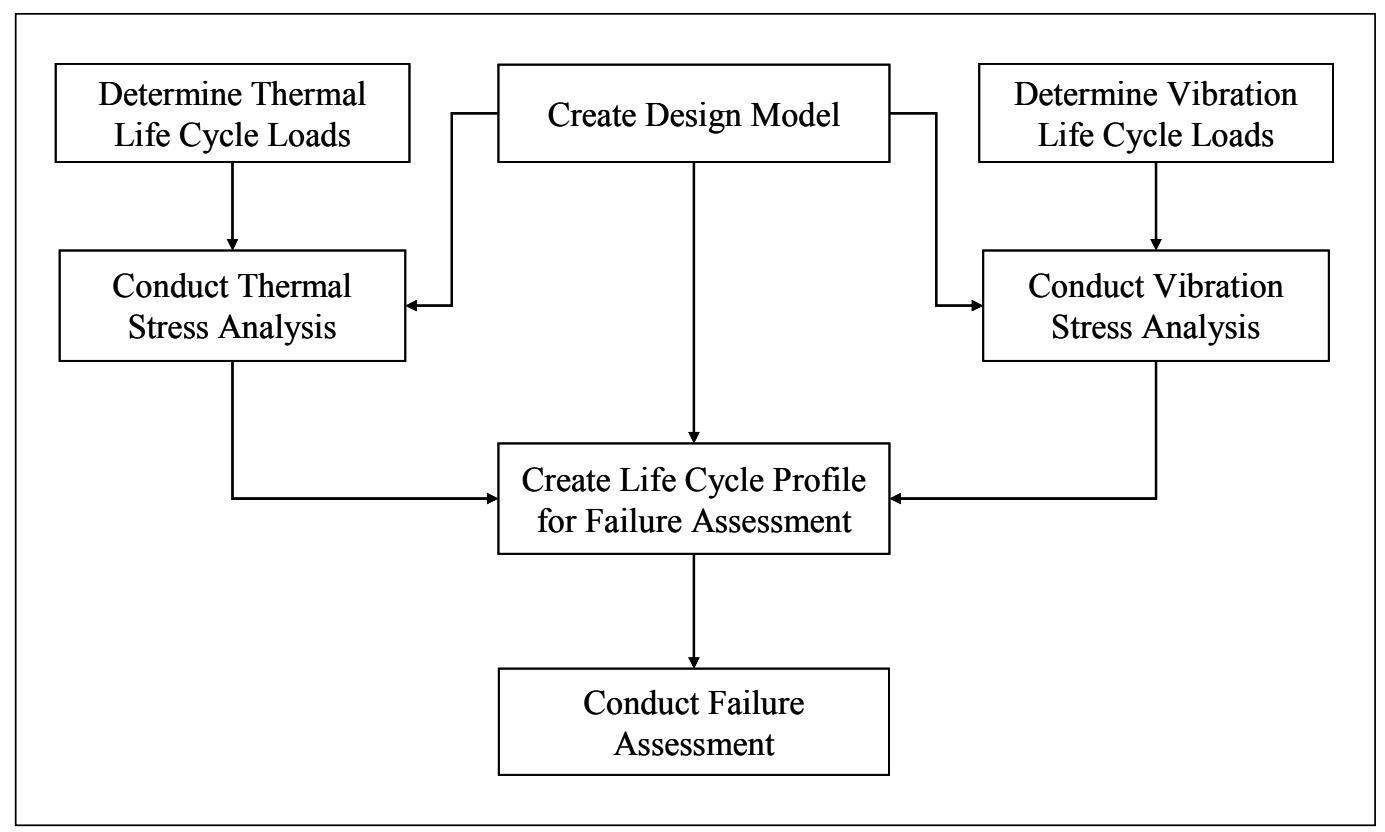

Figure 3. Process flow for the simulation.

\section{Design capture}

In the design capture step, the physical dimensions, functionality, and constitutive elements (e.g., material properties) of the circuit card and all the components on the circuit card were gathered and documented. Data involving the components on the circuit card, the respective part types and dimensions, position on the circuit card, card dimensions, and card and component material properties were collected. For the hardware under review, there was a total of 121 components belonging to seven part types. All components were modeled as insertion mounted. The data was used by the software to generate a model of the circuit card. The aluminum frame was modeled as four separate structural components attached to the circuit card.

\section{Load history characterization}

Load history characterization involved identifying and recording significant life cycle loads and simplifying them for assessment. Field data cannot be used as direct inputs to the damage models because of complexity. Therefore, the data had to be transformed into a simpler form based on damage models and the capability of the assessment tool. The most significant loads for the hardware under review consisted of the vibration acceptance load, the random vibration experienced during flight, the shock upon water impact, and the thermal loads during acceptance test. The thermal loads during the pre-flight operations, flight, recovery, and storage and the vibrations during transportation were minimal. Therefore, the loads were not considered for the virtual remaining life assessment since it was found that those thermal cycles had an insignificant contribution to the total damage of the circuit card. A printed circuit card experiences maximum deflection in its out-of-plane axis compared to the in-plane axes; therefore, only the out-of-plane vibration and shock were considered for virtual remaining life assessment. For the hardware under review, the out-of-plane axis is the $x$ axis. For both random vibration and shock loads, data used in the simulation were more conservative than the actual load. Effects of each modification were quantitatively verified, and it was found that since the duration for each of the segments was short, the effects of the more-conservative estimates did not significantly change the times to failure of the components. 


\section{Vibration load used in simulation}

The random vibration data for each event was provided in the form of curve plots with PSD in units of $\mathrm{g}^{2} /$ hertz $(\mathrm{Hz})$ along the vertical axis, and frequency, in units of $\mathrm{Hz}$ along the horizontal axis. There were 206 data points in each curve. Each PSD profile was simplified by selecting a set of PSD data points that covered the acceleration peaks of the original PSD profile, thereby accounting for the magnitudes of the accelerations at the resonant frequencies. ${ }^{5}$ The total energy of the random vibration is related to its root-mean-square (RMS) value, which can be estimated from the area under the curve. This relationship is given by equation $1:^{9}$

$$
\sqrt{\text { Area }}=\sqrt{G^{2} / \mathrm{Hz}(\mathrm{Hz})}=\sqrt{G^{2}}=G_{R M S}
$$

The simplified PSD profile has a higher RMS value than the original profile. The RMS value of the original curve is 4.4 whereas the RMS value of the simplified curve is 7.4 . Therefore, the damage estimation is conservative. Figure 4 shows an original PSD curve and the reduced PSD curve for event 22 of the flight.

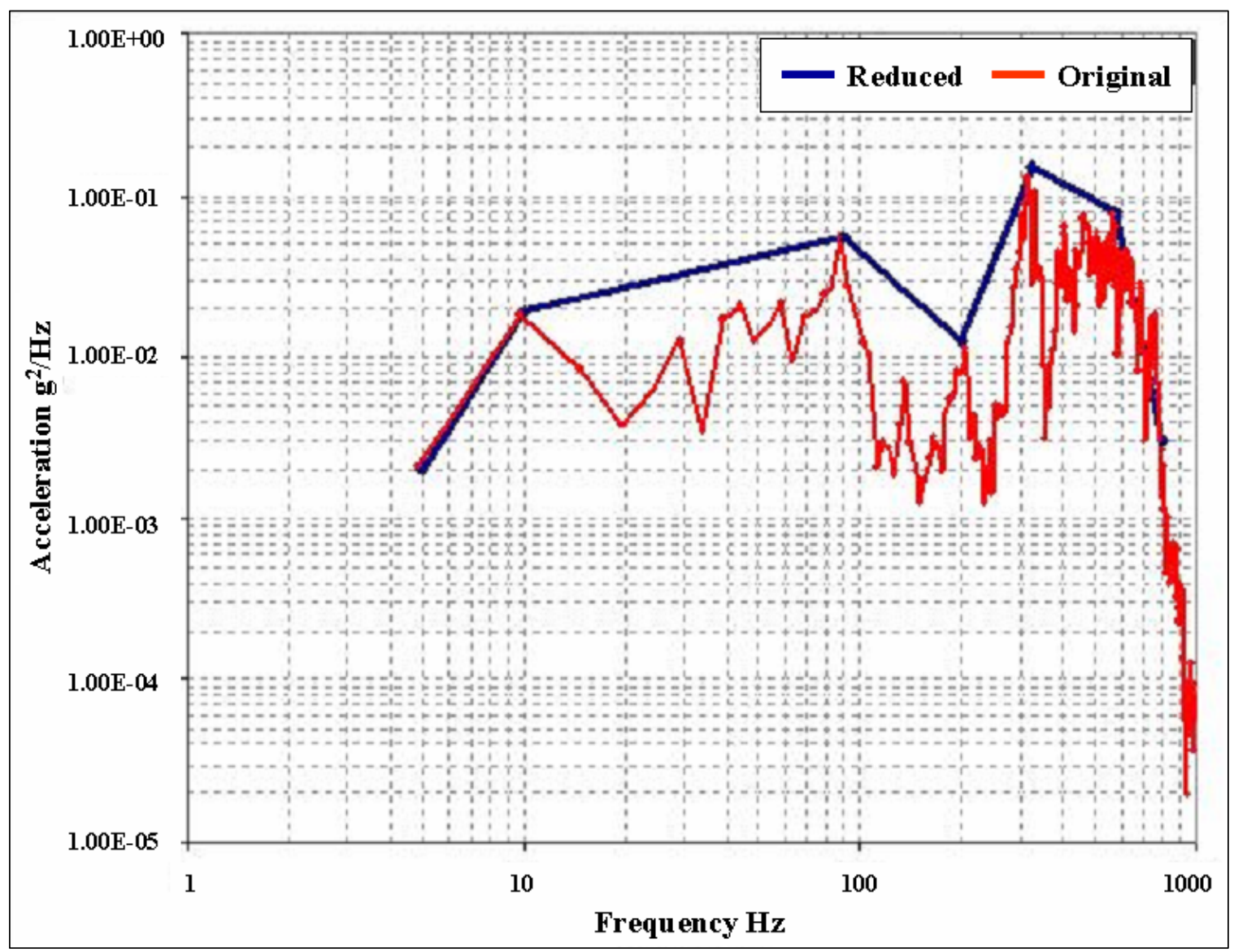

Figure 4. Original and reduced PSD profiles for event 22 for vibration-isolated flight.

This simplification process was conducted for 31 events for the flight with vibration isolation and the flight without vibration isolation. A similar process was used to simplify the pre-flight vibration acceptance test PSD profile. 


\section{Shock load used in simulation}

The 32nd event of the SRB flight is the water impact or shock event. The shock load was first modeled as an overstress load to estimate whether the components on the circuit card would survive the shock. In the simulation, the component interconnects survived the overstress shock load. It was understood that overstress load was inadequate since it did not account for the accumulated damage caused by multiple shocks. For simulating the accumulated damage caused by the shock during the water impact event, the shock load was modeled as a sinusoidal harmonic load. Figure 5 shows the shock data representation as harmonic load.

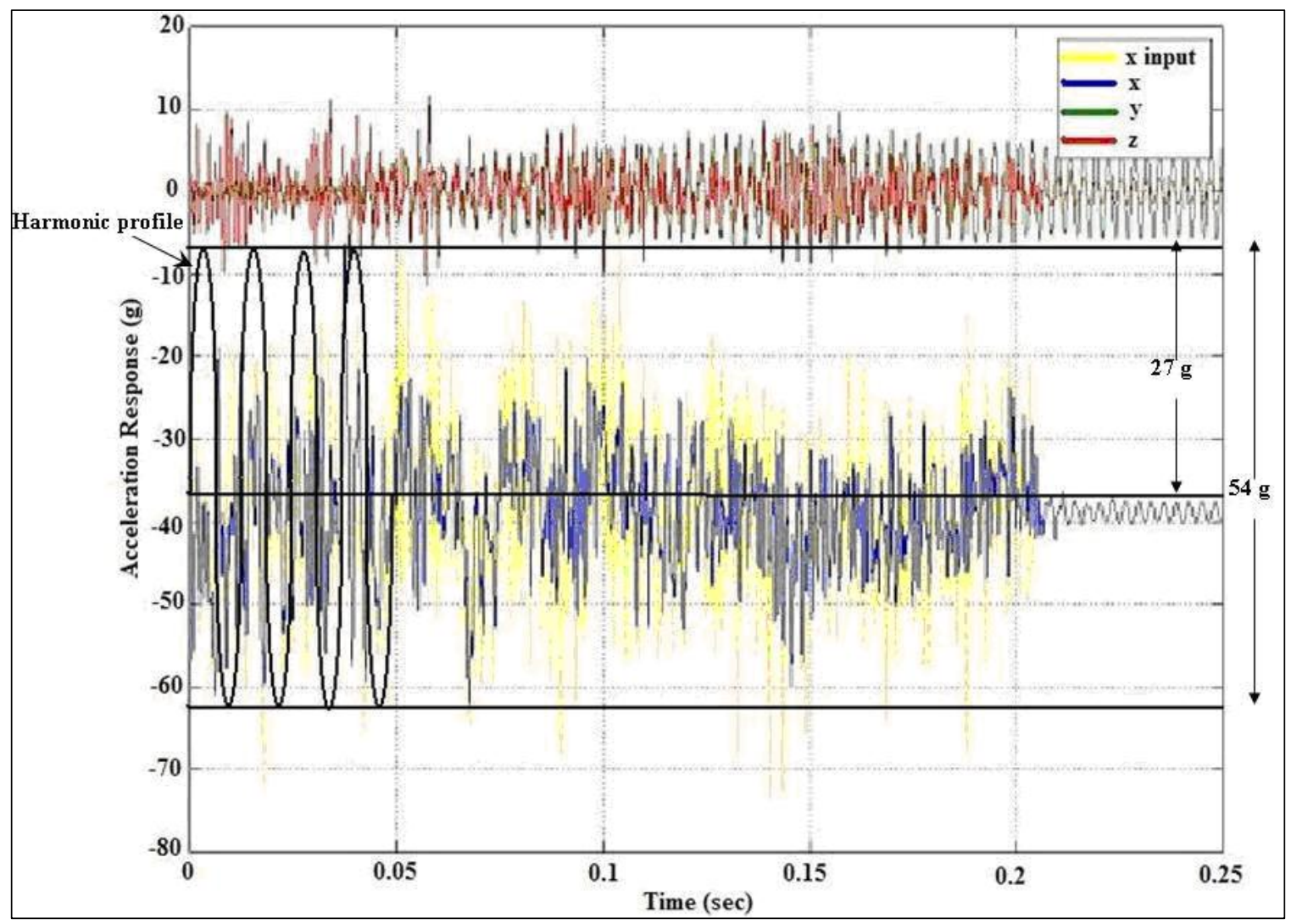

Figure 5: Harmonic approximation of shock data.

Shock profile in the out-of-plane axis, which corresponds to the $x$ axis in Figure 5, was considered for the assessment. The maximum and minimum values of the shock load response were extracted from the time history data. The highest peak-to-peak value was $54 \mathrm{~g}$. A bound was created on either side of the mean with the limit being $27 \mathrm{~g}$. As a worst-case condition, the shock load due to water impact was approximated as harmonic vibration load with a 27 -g peak acceleration. This harmonic load duration for each flight was $0.2 \mathrm{sec}$ with a frequency equal to the natural frequency of the circuit card. Thus the whole shock load consisted of 110 cycles, each with a 27 -g peak acceleration and lasting for approximately 2 milliseconds. Since most of the energy transferred due to vibration occurs when the circuit card is flexing at natural frequency, elimination of other frequency levels is more than compensated by the use of the maximum value of acceleration over the complete time domain. 


\section{Load transformation}

The load transformation step took life cycle load history and circuit card architecture as input and produced the stress fields (e.g., temperature, displacement, and curvature). The load transformation process utilized the characterized loading conditions to estimate the effect of these loads on the circuit card. Using the software, the circuit card curvature due to the vibration and shock loading conditions was estimated.

The fundamental step in calculating the vibration fatigue life of the components mounted on a printed circuit card is the determination of the natural frequencies and the corresponding mode shapes of the card. The dynamic card displacements are inversely proportional to the natural frequencies of the circuit card, and a slight increase in the natural frequency of the circuit card can reduce the maximum amplitude of the displacements.

The vibration, shock, and thermal analyses are dependent on the method of mounting the printed circuit card in its casing. The circuit card was assumed to be wedge-locked on three sides along the aluminum frame and simply supported on the fourth side. After fixing the mounting conditions of the software model, the simplified random vibration loading profiles were used as input to the software. The software estimated the natural frequencies of the circuit card and the displacements of the components and the card. The first natural frequency of the circuit card estimated by the software was $270 \mathrm{~Hz}$.

The shock loading mechanism considered was fatigue failure due to wear-out. The failure model considered was for interconnect failure due to repeated stress reversals under a harmonic vibration load. The circuit card and component displacements and curvatures due to the $27-\mathrm{g}$ harmonic load were estimated.

The thermal acceptance test temperature cycling profile was input to the software to determine the effect of the temperature cycling on the circuit card. The software calculated the damage ratio at each solder joint interconnect due to the temperature cycling load.

\section{Damage assessment}

The damage assessment for the component solder joint interconnect was conducted using the failure analysis feature of the software. The failure analysis module used a failure model consisting of a stress model and a damage model. Stress models correlate the environmental and operational loads, package architecture, and material properties to stress, strain, and energy distributions within the interconnects. Damage models estimate the number of cycles to failure. Under vibration loading, the fatigue failure is termed high cycle (greater than 1 million cycles) and is modeled by a Basquin high-cycle fatigue relation. The model defines life in terms of number of cycles to failure $\left(N_{f}\right)$ :

$$
N_{f}=C(\Delta \sigma)^{b}
$$

where $C$ and $b$ are material constants and $\Delta \sigma$ is a stress metric that represents the worst case stress in the package-to-circuit card interconnect due to the vibration loading condition. As noted earlier, the shock load lasting for $0.2 \mathrm{sec}$ had been approximated as a harmonic vibration load with a frequency of 110 cycles, each with a 27 -g peak acceleration. The Basquin relationship was used, assuming that strain at the solder interconnect stayed in a region where no significant plastic 
damage occurred. For the assessment of life under temperature excursions during the flight, the expected life was expressed in cycles for failure and was characterized as a low-cycle fatigue. In this assessment, a Manson-Coffin relation is assumed:

$$
N_{f}=\frac{1}{2}\left(\frac{\Delta \gamma}{2 \varepsilon_{f}}\right)^{\frac{1}{c}}
$$

where $c$ and $\varepsilon_{f}$ are material properties and $\Delta y$ is the stress metric for the interconnect due to the defined temperature cycle. In the damage assessment step, the damage for each part was defined in terms of damage ratio $\left(D_{R}\right)$, which is the ratio of the number of cycles applied to the number of cycles the part can survive. The damage due the individual stress segment $\left(D_{R i}\right)$ is given as:

$$
D_{R i}=\frac{N_{i}^{\text {applied }}}{N_{i}^{\text {available }}}
$$

where $N_{i}^{\text {applied }}$ is the number of cycles applied and $N_{i}^{\text {available }}$ is the number of cycles the structure can survive. When considering multiple stress segments, the total damage $\left(D_{\text {total }}\right)$ is calculated using Miner's rule: ${ }^{9}$

$$
D_{\text {total }}=\sum_{i} \frac{N_{i}^{\text {applied }}}{N_{i}^{\text {available }}}
$$

For the circuit card, the damage ratio for the interconnects for each component due to each random vibration load, shock load, and temperature cycling load was estimated. The total damage ratio for the interconnects for each component was the sum of the damage ratios due to random vibrations, shocks, and temperature cycling from the life cycle loading experienced by the circuit card. For example, damage was assessed for each random vibration load (31 in all) for one mission. The damage caused by each random vibration load was added to get the total damage caused due to random vibration for that particular mission. Likewise, the damage due to random vibration for each of the remaining seven missions was calculated. The total damage due to random vibration during flight was the sum of the damages calculated for all eight missions. Thus the final damage estimate was the sum of the damage due to random vibration load during 8 flights, shock during 8 flights, random vibrations during 15 vibration acceptance tests, and temperature cycling during 27 thermal acceptance tests. This total damage ratio due to past life cycle loads was termed as damage to date $\left(D_{T D}\right)$. Table 1 shows the summary of the past loading history.

It was assumed that one future life cycle would consist of one vibration isolated flight, two exposures to the acceptance level vibration, and three temperature acceptance tests. The load profiles were assumed to be the same as the past load profiles. Re-applying the random vibration, shock, and temperature cycling loads to a software model for one future life cycle, the expected total damage per mission $\left(D_{M}\right)$ was estimated. Table 2 shows the assumed future loading per mission. 
Table 2. Loads per future mission.

\begin{tabular}{|l|l|c|}
\hline \multicolumn{1}{|c|}{ Life Cycle Condition } & \multicolumn{1}{c|}{ Load Type } & $\begin{array}{c}\text { Number of Exposures } \\
\text { per Mission }\end{array}$ \\
\hline Vibration acceptance test & Random vibration & 2 \\
\hline Thermal acceptance test & Temperature cycling & 3 \\
\hline Flight (vibration isolated) & Random vibration and shock & 1 \\
\hline
\end{tabular}

The software calculated the total damage ratio for the interconnects for each component. The components were ranked based on the damage to the interconnects. This ranking helped in identifying the potential failure sites on the printed circuit card under life cycle loads. The 121 components of the circuit card were also ranked based on the respective damage ratios.

\section{Calculating remaining life}

The failure criterion $\left(D_{f}\right)$ for an interconnect is a total damage ratio equal to 1 . The remaining life of the printed circuit card was determined by finding the time under the applied life cycle load conditions at which the worst-case damage ratio for any interconnect became equal to 1 . From the damage to date and the expected damage per future life cycle, the remaining life of the printed circuit card was estimated. For the circuit card, the number of survivable missions $\left(N_{M}\right)$ is shown as:

$$
N_{M}=\frac{\left(D_{f}-D_{T D}\right)}{D_{M}}
$$

where $D_{T D}$ is damage to date.

Table 3 shows the estimate of survivable missions for the top 10 components of the circuit card with the worst-case damage ratios.

Table 3. Estimate of survivable missions.

\begin{tabular}{|l|c|c|c|}
\hline \multicolumn{1}{|c|}{ Failure Site } & $\mathbf{D}_{\mathbf{T D}}$ & $\mathbf{D}_{\mathbf{M}}$ & $\mathbf{N}_{\mathbf{M}}$ \\
\hline P1 (connector) & 0.25 & $3.18 \mathrm{E}-02$ & 22 \\
\hline CR14 (diode) & 0.16 & $2.08 \mathrm{E}-02$ & 39 \\
\hline CR6 (diode) & 0.13 & $1.64 \mathrm{E}-02$ & 52 \\
\hline CR10 (diode) & 0.12 & $1.52 \mathrm{E}-02$ & 57 \\
\hline Tb (transformer) & 0.10 & $1.31 \mathrm{E}-02$ & 68 \\
\hline CR2 (diode) & 0.09 & $1.20 \mathrm{E}-02$ & 75 \\
\hline Ta (transformer) & 0.09 & $1.18 \mathrm{E}-02$ & 76 \\
\hline Q15 (transistor) & 0.014 & $1.59 \mathrm{E}-03$ & 619 \\
\hline Q11 (transistor) & 0.014 & $1.58 \mathrm{E}-03$ & 621 \\
\hline Q3 (transistor) & 0.014 & $1.58 \mathrm{E}-03$ & 623 \\
\hline
\end{tabular}

The connector P1 is secured to the card with screws on both ends. Therefore, the connector failure was ignored and the survivable missions value of the diode was used as a baseline for predicting the remaining life of the circuit card. It was estimated that the circuit card could survive 39 more launch missions. 


\section{SUMMARY AND OBSERVATIONS}

In this study, the process of virtual remaining life assessment of an electronic circuit card was explored. The method was demonstrated through a case study in which the remaining life of a printed circuit card was estimated from the value of the damage accumulated in the componentto-circuit card interconnects. The damage to date due to past life cycle loads and the expected damage per future life cycle were used for virtual remaining life assessment of the printed circuit card. The virtual remaining life assessment of the hardware under study estimated that the circuit card would survive 39 more missions.

The availability of the collected thermal and vibration data by NASA made it possible to make assumptions about the future life cycle of the circuit card during Shuttle launches. The assumptions regarding the simplified versions of vibration loads could be validated due to the use of the rapid simulation tool. This study also used the harmonic modeling of shock for the first time and took the effect of shock beyond commonly used overstress models.

\section{ACKNOWLEDGEMENTS}

The authors thank NASA, BD Systems, United Space Alliance, and CALCE at the University of Maryland for supporting this study. The virtual remaining life assessment was conducted using software developed by the CALCE.

\section{REFERENCES}

1. Hu, J., D. Barker, A. Dasgupta, and A. Arora. 1992. Role of Failure Mechanism Identification in Accelerated Testing. Proceedings of Annual Reliability and Maintainability Symposium 181-88. Las Vegas, NV: RAMS.

2. Valentin, R., M. Osterman, and B. Newman. 2003. Remaining Life Assessment of Aging Electronics in Avionic Applications. Proceedings of Annual Reliability and Maintainability Symposium 313-18. Tampa, FL: RAMS.

3. Cunningham, J., R. Valentin, C. Hillman, A. Dasgupta, and M. Osterman. 2001. A Demonstration of Virtual Qualification for the Design of Electronic Hardware. Proceedings of the Institute of Environmental Sciences and Technology. Rolling Meadows, IL: IEST.

4. Valentin, R., J. Cunningham, M. Osterman, A. Dasgupta, M. Pecht, and D. Tsagos. 2002. Virtual Life Assessment of Electronic Hardware Used in the Advanced Amphibious Assault Vehicle (AAAV). Proceedings of the IEEE Winter Simulation Conference. New York: IEEE.

5. Shetty, V., D. Das, M. Pecht, D. Hiemstra, and S. Martin. 2002. Remaining Life Assessment of Shuttle Remote Manipulator System End Effector. Proceedings of the 22nd Space Simulation Conference. Ellicott City, MD: NASA.

6. Mishra, S., M. Pecht, T. Smith, I. McNee, and R. Harris. 2002. Remaining Life Prediction of Electronic Products using Life Consumption Monitoring Approach. Proceedings of the European Microelectronics Packaging and Interconnection Symposium June. Cracow, Poland: IMAPS.

7. Osterman, M., A. Dasgupta, and T. Stadterman. 2002. Virtual Qualification of Electronic Hardware. In Case Studies in Reliability and Maintenance. Eds. W. R. Bilschke and D. N. P. Murthy. New York: John Wiley \& Sons.

8. Moritz, K. Human Space Flight: Background and Status. NASA/Kennedy Space Center. http://www.spaceflight.nasa.gov/shuttle/reference/shutref/srb/srb.html. Updated April 7, 2002. (Accessed Sept. 26, 2003.)

9. Steinberg, D. S. 1988. Vibration Analysis for Electronic Equipment. New York: John Wiley $\&$ Sons. 


\section{ABOUT THE AUTHORS}

Sony Mathew received an MS in mechanical engineering from A. James Clark School of Engineering of the University of Maryland, College Park, in May 2005. He is currently working as a faculty research assistant at the Center for Advanced Life Cycle Engineering (CALCE) in the Mechanical Engineering Department of the University of Maryland, College Park. He completed a BE in mechanical engineering in 1997 and an MBA in 1999, both from Pune University, India.

Diganta Das has a PhD in mechanical engineering from the University of Maryland, College Park, and a B.Tech in manufacturing science and engineering from the Indian Institute of Technology. He is an assistant research scientist in the CALCE. Dr. Das has published in the areas of electronic part uprating and operational environments of electronic parts, organized international conferences and workshops, and worked in international standards developments. $\mathrm{He}$ is the technical editor for the IEEE Standards Society working group SCC 37. He is a Six Sigma black belt from the Celestica Corporation. He serves on the editorial board of Microelectronics Reliability and is a member of IEEE and IMAPS.

Michael Osterman, with a $\mathrm{PhD}$ in engineering mechanics from the University of Maryland, College Park, is a senior research scientist and the CALCE Consortium Director at the University of Maryland. He heads the development of simulation-based failure assessment software at CALCE, and is one of the principal researchers in the CALCE effort to develop simulation models for temperature cycling fatigue of $\mathrm{Pb}$-free solder. He has been involved in the study of tin whiskers since 2002 and has authored several articles related to the tin whisker phenomenon. Dr. Osterman has written various book chapters and numerous articles in the area of electronic packaging. He is a member of IEEE, ASME, and SMTA.

Michael Pecht is a Chair Professor and the director of the Center for Advanced Life Cycle Engineering (CALCE) at the University of Maryland, College Park. Dr. Pecht has an MS in electrical engineering and an $\mathrm{MS}$ and $\mathrm{PhD}$ in engineering mechanics from the University of Wisconsin at Madison. He is a Professional Engineer, an IEEE Fellow, an ASME Fellow, a Westinghouse Fellow, and a Senior Member of IEST. He has written 11 books on electronics products development and six books on the electronics industry in Southeast Asia. He served as chief editor of the IEEE Transactions on Reliability for eight years and on the advisory board of IEEE Spectrum. He is currently the chief editor for Microelectronics Reliability. He serves as a consultant for various companies, providing expertise in strategic planning, design, test, and risk assessment of electronic products and systems.

Robin Ferebee began his career as a cooperative education student at the NASA Marshall Space Flight Center, Huntsville, AL, in 1975, working with the engineers who developed the acoustic environments for the Space Shuttle. Upon graduation in 1980, he went to work in the Structural Dynamics Division at Marshall, developing acoustic, vibration, and shock criteria for the Space Shuttle solid rocket boosters (SRB). During that time, he published papers on vibration criteria development and random vibration load derivation. $\mathrm{He}$ is currently employed at Marshall's Kennedy Space Center Resident Office, where he supports the SRB chief engineer on dynamics issues.

Joseph Clayton is currently vice president of the Advanced Technology Division of BD Systems, Inc., Huntsville, AL, a subsidiary of SAIC Corporation. He holds a BS in mechanical engineering from the University of Central Florida and a MS in computer science from the Florida Institute of Technology. His division specializes in structural analysis, multibody dynamic analysis, loads analysis, vibro-acoustic analysis, guidance, navigation and control design and analysis, and flight software development. The division is primarily NASA-based and supports all aspects of the current Space Shuttle and has current contracts supporting the Crew Launch Vehicle (CLV) being developed as part of the Space Exploration Initiative. 